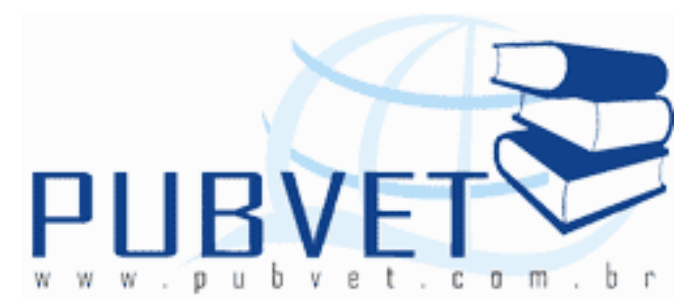

PUBVET, Publicações em Medicina Veterinária e Zootecnia.

\title{
Características histopatológicas de fígado de cães intoxicados experimentalmente com sementes de Crotalaria spectabilis
}

Carolina Bellodi ${ }^{1}$, Mário Roberto Hatayde ${ }^{2}$, Rosemeri de Oliveira Vasconcelos ${ }^{3}$

${ }^{1}$ Doutoranda em Medicina Veterinária, Universidade Estadual Paulista, UNESP Campus Jaboticabal, SP, Brasil. E-mail: carolbellodi@hotmail.com

${ }^{2}$ Professor do Curso de Medicina Veterinária da Universidade Estadual Paulista, UNESP - Campus Jaboticabal, SP, Brasil.

${ }^{3}$ Professora Adjunta do Departamento de Patologia Veterinária, Universidade Estadual Paulista, UNESP - Campus Jaboticabal, SP, Brasil.

\section{Resumo}

Sabe-se que a Crotalaria spectabilis é amplamente utilizada como adubo verde e nematóides controladores, com que se espalha facilmente, misturando-se com o milho e infectando outras rações de cereais. O objetivo deste estudo foi avaliar os efeitos tóxicos das sementes de C. spectabilis, quando triturados e misturados com os cães de alimentação. Este estudo utilizou 12 cães foram divididos em três grupos de quatro animais. Os tratamentos foram divididos em grupos, cada grupo receberam, respectivamente, 0,2, 0,4 e 0,6\% de sementes de $\mathrm{C}$. spectabilis, durante 28 dias, os quais foram esmagados e adicionados à dieta. Para exames histopatológicos foram extraídos de uma biópsia hepática, utilizando um tipo de agulha TRU-CUT $®$. Observado hepatócitos inchadas, vacuolização das células dos sinusóides, necrose focal, 
cariomegalia anisocitose, células de Kupffer com diferentes pigmentações, fibrose e colestase em hepatócitos caracterizadas doença hepática. Conclui-se, com base em exames histopatológicos, desde que as concentrações de sementes de $C$. spectabilis $0,2,0,4$ e $0,6 \%$ ao longo de 28 dias, foram tóxicos para cães.

Palavras-chave: Alcalóides pirrolizidines, cães, histopatologia, envenenamento.

\title{
Histopathological features of liver of dogs poisoned experimentally with Crotalaria spectabilis seeds.
}

\begin{abstract}
It is known that the Crotalaria spectabilis is widely used as green manure and for controlling nematodes, with that spreads easily, mingling with the infecting maize and other cereal rations. The aim of this study was to evaluate the toxic effects of the seed of $C$. spectabilis, when crushed and mixed with the feed dogs. This study used 12 dogs divided into three groups of four animals. The treatments were divided into groups, each group received respectively $0,2,0,4$ and $0,6 \%$ of seeds of $C$. spectabilis, for 28 days, which were crushed and added to the diet. For histopathological examinations were extracted from a liver biopsy, using a needle type TRU-CUT ${ }^{\circledR}$. Observed swollen hepatocytes, vacuolization of cells in the sinusoids, focal necrosis, anisocytosis cariomegalia, Kupffer cells with different pigmentation, fibrosis and cholestasis in hepatocytes characterized liver disease. We conclude, based on histopathological examinations, provided that the concentrations of seeds of $C$. spectabilis $0,2,0,4$ and $0,6 \%$ during the 28 days were toxic to dogs.
\end{abstract}

Keywords: Alkaloids pirrolizidines, dogs, histopatology, poisoning. 


\section{INTRODUÇÃO}

Com a multiplicidade de produtos lançados no mercado "pet" o controle de qualidade deve ser a maior preocupação das indústrias de rações, pois, sem isso, aumenta muito o risco de contaminação por impurezas, encontrado na própria matéria prima. Plantas do gênero Crotalaria são utilizadas em solos pobres, como adubação verde, pelo seu alto poder de fixação de nitrogênio e também para controle de nematóides, devido ao seu princípio ativo tóxico (4). Uma vez incorporada a terra, cresce junto às plantações de milho e outros cereais e suas sementes acabam por misturar-se durante o processo de colheita. Entretanto, por se tratar de uma semente extremamente pequena, 4 x 3 x 2mm, passa desapercebida no meio do milho ou da soja que são vendidos às empresas produtoras de alimentos para animais, em consequência disso, pode intoxicá-los. As substâncias tóxicas contidas nas plantas do gênero Crotalaria são por sua vez alcalóides pirrolizidínicos (APs). Os APs encontrados em maior quantidade na $C$. spectabilis, é a monocrotalina, localizado em várias partes da planta, sendo a semente a parte mais tóxica $(14,15)$. Para exercerem sua toxicidade, seja ela aguda ou crônica, os APs necessitam de uma ativação metabólica, essencial para exercerem sua genotoxicidade. A monocrotalina no fígado produz necrose das células parenquimais centrolobulares, danos às células endoteliais das vênulas centrais e dos sinusóides, congestão e dilatação dos sinusóides e hemorragia. Uma consequência dos danos às células endoteliais vasculares é a ativação do sistema de coagulação. Durante a injúria vascular, as propriedades anticoagulantes e pró-fibrinolíticas das células endoteliais são perdidas, e a cascata de coagulação é iniciada através de fatores teciduais $(1,3)$.

A biópsia hepática percutânea com agulha cortante tipo TRU-CUT® pode ser uma fonte valiosa de informações quanto aos diversos parâmetros relacionados à função hepática em animais, bem como uma forma auxiliar de diversas lesões que acometem o fígado. Além disso, a biópsia hepática permite diagnosticar as lesões antes que os sinais clínicos tornem-se aparentes, 
diminuindo as perdas econômicas ou mortalidade dos animais afetados $(7,8)$. Assim, através deste trabalho pretende-se verificar os efeitos histológicos da ingestão experimental de sementes de $C$. spectabilis quando trituradas e misturadas à ração de cães por um período determinado.

\section{MATERIAL E MÉTODO}

Foram utilizados 12 cães, sem raça definida, provenientes do Centro de Pesquisa em Sanidade Animal, CPPAR localizado na Universidade Estadual Paulista FCAV-UNESP Campus de Jaboticabal, onde permaneceram alojados individualmente em canis localizados no Hospital Veterinário Governador Laudo Natel. O presente trabalho está de acordo com os princípios éticos na experimentação animal, adotado pelo Colégio Brasileiro de Experimentação (COBEA), da Universidade Estadual Paulista UNESP Campus Jaboticabal e foi aprovado pela Comissão de Ética e bem estar animal, em reunião de 14 de agosto de 2008, sob protocolo número 0016735-08. Os grupos foram manejados da seguinte forma: $G_{1}$ - Ração comercial $+0,2 \%$ de sementes de C. spectabilis, $\mathrm{G}_{2}$ - Ração comercial $+0,4 \%$ de sementes de C. spectabilis, $\mathrm{G}_{3}$ Ração comercial $+0,6 \%$ de sementes de $C$. spectabilis, por quatro semanas. Dieta composta de ração comercial, conforme as recomendações do National Research Council - NRC (2006) e água ad. libitum.

As biópsias hepáticas foram realizadas, por meio da técnica com agulha tipo TRU-CUT ${ }^{\circledR}$, em três momentos diferentes: $M_{0}$ (ração comercial sem adição de sementes), $M_{14}$ (14 dias de ingestão de $C$. spectabilis) e $M_{28}$ (28 dias de ingestão de $C$. spectabilis) do experimento. Após estes procedimentos as amostras de fígado foram armazenadas em solução de formalina a $10 \%$, e encaminhadas ao Departamento de Patologia Veterinária da FCAV - UNESP, Jaboticabal onde foram processadas. As lâminas histológicas foram coradas com Hematoxilina e Eosina (HE) e Tricrômio de Masson (TM), a leitura foi realizada em microscopia de luz. 


\section{RESULTADOS}

Os resultados obtidos no presente estudo revelaram o grau de toxicidade das sementes de C. spectabilis em cães. Observou-se que os animais alimentados com diferentes percentuais das sementes, apresentaram sinais clínicos de diversas intensidades apresentando, portanto, variações de animal para animal nos diferentes grupos.

Foram encontradas alterações microscópicas, em todos os grupos, mas com diferentes intensidades, ao longo do período experimental, que estão citadas na tabela 1.

No $\mathrm{G}_{3}$ onde os animais receberam a maior quantidade das sementes de C. spectabilis observou-se colestase, em alguns animais. Notaram-se extensas áreas de fibrose (Figura 1) e focos de hemorragia, e, grande quantidade de nucléolos evidentes nos núcleos de hepatócitos.

\section{DISCUSSÃO}

Esse trabalho evidenciou que as sementes de Crotalaria spectabilis adicionadas à ração de cães, por um período de 28 dias causaram toxicidade à espécie. As análises histopatológicas encontradas no fígado dos cães intoxicados experimentalmente com sementes de $C$. spectabilis se assemelham as lesões encontradas por outros autores, com diferentes animais e em diferentes porcentagens das sementes tóxicas $(2,5,6,9,10,11,12)$.

De acordo com FU e colaboradores (2002), as lesões provocadas aos hepatócitos devido a diversas substâncias tóxicas podem ser reversíveis ou irreversíveis dependendo do grau da lesão a membrana basal das células hepáticas, levando à substituição por tecido conjuntivo fibroso. Este processo evidencia evolução mais crônica, quando os agentes químicos agressores estiverem em quantidades elevadas ou existir exposição contínua. A matriz extracelular desempenha um papel importante em lesões hepáticas crônicas e tem sido estuda em modelos de intoxicação experimental por Torres \& Coelho (2008). No presente estudo as lesões foram mais crônicas, tais como fibrose. 
Tabela 1. Achados histopatológicos em fígados de cães intoxicados experimentalmente por Crotalaria spectabilis, nas concentrações de $0,2 \%(\mathrm{G} 1), 0,4 \%(\mathrm{G} 2)$ e $0,6 \%$ (G3), por 28 dias.

\begin{tabular}{|c|c|c|c|}
\hline Lesões histopatológicas & $\overline{\mathbf{G}_{1}}$ & $\overline{\mathbf{G}_{2}}$ & $\overline{\mathbf{G}_{3}}$ \\
\hline Degeneração Hidrópica & ++ & +++ & ++++ \\
\hline $\begin{array}{l}\text { Vacuolização de células } \\
\text { sinusoidais }\end{array}$ & +++ & ++ & + \\
\hline Necrose focal & + & ++ & +++ \\
\hline $\begin{array}{l}\text { Linfócitos, plasmócitos + } \\
\text { macrófagos com pigmento }\end{array}$ & ++ & ++ & ++++ \\
\hline
\end{tabular}

na região Peri portal

\begin{tabular}{|c|c|c|c|}
\hline Anisocitose & + & + & ++ \\
\hline Cariomegalia & ++ & ++ & + \\
\hline $\begin{array}{l}\text { Leucócitos em região } \\
\text { perivascular }\end{array}$ & ++ & ++ & +++ \\
\hline Fibrose & ++ & +++ & ++++ \\
\hline Proliferação ductal & ++ & ++ & +++ \\
\hline $\begin{array}{l}\text { Deposição de colágeno em } \\
\text { vasos sanguíneos }\end{array}$ & ++ & +++ & ++++ \\
\hline
\end{tabular}

Critério: - sem lesão, + discreto, ++ discreto a moderado, +++ moderado, ++++ moderado a severo, +++++ severo 
A principal fonte de deposição de colágeno nas injúrias crônicas são as células Ito que residem no espaço de Disse. Embora funcionem como células armazenadoras de vitamina A e lipídios, elas são ativadas durante o desenvolvimento da fibrose e transformam-se em células semelhantes à miofibroblastos. O resultado final é um fígado fibrótico nodular onde as células parenquimatosas estão circundadas por intensa formação de tecido conjuntivo estando incapacitada de comunicação com outros hepatócitos e com as vias biliares próximas, tornando esta nova formação celular inútil do ponto de vista fisiológico $(13,15)$. Aspectos tais como, anisocitose, cariomegalia, binucleação em hepatócitos, são sugestivos de tentativa de regeneração pelo tecido hepático. No entanto, a fibrose observada interfere neste processo e impede o fígado de exercer suas funções fisiológicas, em casos avançados.

\section{CONCLUSÃO}

Com base nos resultados obtidos durante o período experimental podemos concluir que as lesões histológicas encontradas no fígado são compatíveis com intoxicação pela ingestão das sementes de Crotalaria spectabilis, nas dosagens de $0,2 \%, 0,4 \%$ e $0,6 \%$ em 28 dias.

\section{REFERÊNCIAS BIBLIOGRÁFICAS}

1.COPPLE, B. L.; GANEY, P. E.; ROTH, R. A. Liver inflammation during monocrotaline hepatotoxicity. Toxicology, v. 190, p. 155-169, 2003.

2.EMMEL, M. W. Livestock Poisoning by Crotalaria spectabilis. Veterinary Medicine. 1943, p. 255-256.

3.FLETCHER, M. T.; McKENZIE, R. A.; BARRY, J. B.; REICHMANN, K. G. Pyrrolyzidine alkaloids in crotalaria taxa from Northern Australia: risk to grazing livestock. J. Agric. Chem., n. 57, p. 311-319, 2009.

4.FU, P. P.; YANG, Y. C.; XIA, Q.; CHOU, M. W.; CUI, Y. Y.; LIN, G. Pyrrolizidine alkaloids tumorigenic components in chinese herbal medicines and dietary suplements. Journal of Food and Drug Analysis, v. 10, n. 4, p. 198 - 211, 2002.

5.GARRIDO, M. S.; SOARES, C. F.; COIMBRA, J. L.; SOUSA, C.S. Management of crotalaria and pigeon pea for control of yam nematode diseases. Summa Phytopatology, v.34, n. 3, p. 222-227, 2008. 
6.HATAYDE, M. R.; ALESSI, A. C.; BERCHIERI-JUNIOR, A.; CAFÉ, M. B.; CURTARELLI, S. M. Estudo experimental sobre a intoxicação de Gallus gallus domesticus com sementes de Crotalaria spectabilis. II- Efeito em aves na fase final de crescimento. Arquivo Brasileiro de Medicina Veterinária e Zootecnia, v. 49. p. 239-249, 1997.

7.MATTOCKS, A. R. Toxicity of pyrrolizidine alkaloids. Nature, v. 217, p. 723-28, 1968

8.Medeiros, M. B. A.; SOUZA, F. F.; NETO, P. I. N.; COELHO K. I. R. Técnica de biópsia hepática guiada pelo ultra-som em bezerros. Rev. Educ. Contin., São Paulo. v. 5, n. 1, p. 94 99. 2002.

9.MELO, A. A. Intoxicação experimental em equinos com sementes de Crotalaria spectabilis. 2010. 65p. Programa de aprimoramento professional em Medicina Veterinária e Saúde Pública, Faculdade de Ciências Agrárias e Veterinárias FCAV UNESP - Jaboticabal, 2010. (dados não publicados).

10.PEREIRA, W. A. B. Alterações clínico-patológicas de galinhas poedeiras (Gallus gallus domesticus) intoxicados esperimentalmente com sementes de Crotalaria spectabilis (Leg. Papilionoidea). 2006. 77p. Dissertação (Mestrado) - Faculdade de Ciências Agrárias e Veterinárias FCAV-UNESP Jaboticabal, 2006.

11.SANTOS, J. C. A.; RIET-CORREA, F.; SIMÕES, S. V. D.; BARROS, C. S. L. Patogênese, sinais clínicos e patologia das doenças causadas por plantas hepatotóxicas em ruminantes e eqüinos no Brasil. Pesquisa Veterinária Brasileira, v. 28, n. 1, p. 1-14, 2008.

12.SOUZA, A. C.; HATAYDE, M. R.; BECHARA, G. H. Aspectos patológicos da intoxicação de suínos por sementes de Crotalaria spectabilis. Pesquisa Veterinária Brasileira. Rio de Janeiro, v.17, n.1, p. 12-18, 1997.

13.TORRES, M. B. A. M.; COELHO, K. I. R. Experimental poisoning by Senecio brasiliensis in calves: quantitative and semi-quantitative study on changes in the hepatic extracellular matrix and sinusoidal cells. Pesquisa Veterinária Brasileira, n. 28, v. 1, p. 43-50, 2008.

14.WANG, P. Y.; YAN, J. FU, P. P.; CHOU, M. W. Human liver microssomal reduction of pyrrolizidine alkaloid $\mathrm{N}$-oxides to form the corresponding carcinogenic parent alkaloid. Toxicology Letters, v. 155, p. 411-420, 2005.

15.WILLIAMS, M. C.; MOLYNEUX, R. J. Occurrence, concentration and toxicity of pyrrolizidine alkaloids in crotalaria seeds. Weed Science., v. 35, p. 476-481, 1987. 